\title{
Analysis of Fe-Ni Thin Films Using the Phenomenological Theory of Electrodeposition
}

\author{
M. Saitou* ${ }^{*}$ and K. Inamine \\ University of the Ryukyus, Department of Mechanical Systems Engineering, 1 Senbaru Nishihara-cho \\ Okinawa, 903-0213, Japan. \\ *E-mail: saitou@tec.u-ryukyu.ac.jp
}

doi: $10.20964 / 2021.02 .44$

Received: 2 October 2020 / Accepted: 25 November 2020 / Published: 31 December 2020

$\mathrm{Fe}-\mathrm{Ni}$ thin films electrodeposited using rectangular pulse voltages over a megahertz frequency range were investigated through scanning electron microscopy-energy dispersive X-ray spectroscopy and Xray diffraction. The $\mathrm{Ni}$ content of the $\mathrm{Fe}-\mathrm{Ni}$ thin films increased with the cathode potential; further, it significantly changed at resonant frequencies when the cathode potential was equal to the $\mathrm{Fe}^{2+}$ or $\mathrm{Ni}^{2+}$ potential barrier, and became constant, which was consistent with the phenomenological theory of electrodeposition. The $\mathrm{Fe}^{2+}$ and $\mathrm{Ni}^{2+}$ potential barriers were determined to be 1.48 and $2.22 \mathrm{~V}$, respectively. The Fe-Ni thin films comprised a body-centred cubic crystal structure, namely, $\alpha-\mathrm{Fe}$, and an amorphous structure $\mathrm{FeNi}_{0.832}$ phase (corresponding to the stoichiometric molar ratio of $\mathrm{Fe}-\mathrm{Ni}$ thin films containing 29.8 at\% Ni). The Fe-Ni films had smooth surfaces, which indicated that they were formed by layer-by-layer growth and not by island growth.

Keywords: Fe-Ni thin film; Phenomenological theory of electrodeposition; $\alpha$-Fe; FeNi ${ }_{0.832}$; Smooth surface

\section{FULL TEXT}

(C) 2021 The Authors. Published by ESG (www.electrochemsci.org). This article is an open access article distributed under the terms and conditions of the Creative Commons Attribution license (http://creativecommons.org/licenses/by/4.0/). 